\title{
Nesfatin-1 Hormone Levels in Patients with Antisocial Personality Disorder and Their Relationship with Clinical Variables
}

\author{
Şüheda Kaya ${ }^{1}$, Filiz Özsoy ${ }^{\bowtie}$, Gülay Taşcl $^{3}$, and Mehmet Kalaycl ${ }^{3}$ \\ ${ }^{1}$ Elazığ Mental Health and Diseases Hospital, Elazığ, Turkey \\ ${ }^{2}$ Department of Psychiatry, Tokat State Hospital, Tokat, Turkey \\ ${ }^{3}$ Elazığ Fethi Sekin City Hospital, Elazığ, Turkey
}

\begin{abstract}
Objective This study aims to investigate the levels of nesfatin-1-hormone in patients with Antisocial Personality Disorder (ASPD) and their relationship with clinical variables.

Methods A total of 90 people (45 ASPD, 45 controls) were included in our study. Sociodemographic Data Form, Beck-Depression-Inventory (BDI), Beck-Anxiety-Inventory (BAI), Barratt Impulsivity Scale (BIS-11), Buss-Durkee-Hostility-Inventory (BDHI) were applied to all participants. Venous blood samples were taken from participants at the same time of the day when they were hungry.

Results It was found that the BDI and BAI scores of the ASPD were higher than those of the controls ( $\mathrm{p}<0.001$, for both scales). The scores in BIS-11; motor and nonplanning-impulsivity subscales were higher than those of the controls $(\mathrm{p}<0.001,0.036$, respectively). The scores obtained by the ASPD were higher in all subscales of BDHI $(\mathrm{p}<0.001)$. For the nesfatin-1-hormone, the values of the ASPD were lower than those of the controls $(\mathrm{p}=0.044)$. No relationship was found between the nesfatin-1-hormone and any other laboratory parameters and applied scales $(\mathrm{p}>0.05)$.

Conclusion This is the first study to examine the nesfatin-1-hormone levels in patients with any personality disorder. Further studies with more participants are needed in different types of personality disorders to understand the relationship between personality disorder and nesfatin-1-hormone levels.

Psychiatry Investig 2020;17(9):889-895
\end{abstract}

Key Words Antisocial personality disorder, Nesfatin-1, Impulsivity, Aggression.

\section{INTRODUCTION}

Antisocial Personality Disorder (ASPD) is included in "ype B personality disorders" in the Fifth Edition of Diagnostic and Statistical Handbook of Mental Disorders (DSM-5). Its main feature is an antagonism associated with criminal behavior, violating and not caring about the rights of others. According to the DSM-5 criteria, aggressive behavior patterns that start in childhood and continue throughout life, and poor self-control ability and risk-taking behaviors are transformed into a lifestyle. ${ }^{1}$ Although the etiology of ASPD can not be fully understood; it was tried to be revealed by fam-

\footnotetext{
Received: February 20, 2020 Revised: May 28, 2020

Accepted: June 30, 2020

$\triangle$ Correspondence: Filiz Özsoy, MD

Department of Psychiatry, Tokat State Hospital, Yeni District, 60100 Center, Tokat, Turkey

Tel: +90 0505923 19 82, Fax: +90 03562145400

E-mail: flzkoseoglu82@gmail.com

(a) This is an Open Access article distributed under the terms of the Creative Commons Attribution Non-Commercial License (https://creativecommons.org/licenses/bync/4.0) which permits unrestricted non-commercial use, distribution, and reproduction in any medium, provided the original work is properly cited.
}

ily-oriented and genetic studies, environmental factors and brain imaging methods. It was determined that there is a decrease in prefrontal cortex volume, gray matter volume, frontal lobe anisotropy, and additionally, there are microstructural abnormalities in the frontal lobe..$^{2-4}$ In addition to the morphological changes in the brain, the changes in the Hypothalamus-Pituitary-Adrenal (HPA) axis were also reported in studies. ${ }^{5,6}$ It was found that there is a change in the HPA axis response to stress in severe antisocial behaviors. ${ }^{5}$ It was shown that aggression, aggressive behavior, and personality disorder are associated with HPA axis responses and cortisol levels. ${ }^{\text {? }}$

The nesfatin-1 hormone is a hypothalamus hormone that plays a role in nutrition and maintaining the body energy balance. Additionally, it has been reported to play a role in the regulation of the stress response of the central nervous system. ${ }^{8}$ The studies in the literature show that changes in the level of nesfatin-1 hormone occur in stress-related situations and psychiatric diseases. ${ }^{8-10}$ Studies on nesfatin-1 hormone levels were performed in patients diagnosed with Major Depressive Disorder (MDD), Anorexia Nervosa (AN), Bipolar Affective Disor- 
der (BAD), and Alcohol Use Disorder (AUD). ${ }^{8,10-12}$ No other study investigating the relationship between aggression and personality disorders, and the nesfatin-1 hormone levels was found in the literature. In our study, based on the response changes in the HPA axis in violent behaviors, we assumed that the levels of the nesfatin-1 hormone levels in patients with ASPD may differ from those of the healthy controls. Based on this hypothesis, we aimed to examine the nesfatin-1 hormone levels in ASPD patients by comparing them with those of the healthy controls. Secondly, we aimed to determine the aggression, impulsivity levels of the ASPD group and the relationship with the nesfatin-1 hormone levels.

\section{METHODS}

\section{Ethical procedure}

The study was approved by Elazıg Firat University Clinical Research Ethics Committee (No: 06-10). The study was carried out in accordance with the Helsinki Declaration. ${ }^{13}$

\section{Inclusion and exclusion criteria}

The study included 45 people diagnosed with "Antisocial (Extra-Societal) Personality Disorder" according to the DSM5 criteria, who were followed-up or were inpatients at Elazig Mental Health and Diseases Hospital and Elazig Fethi Sekin City Hospital. A total of 45 people who could match the personality disorder group in terms of demographic data such as age, marital status, education level, and employment status were included as the healthy control group. Volunteers who were literate and could give written consent were included in the study. People with a diagnosis of Axis I, other than MDD, with a metabolic disease, an endocrine, autoimmune, neoplastic disease those who did not want to participate in the study were excluded from the study. In addition, obese individuals, who had body mass index 30 and above, because that may affect hormone distribution, were excluded. All participants were given information about the study. Written consent was obtained from those who agreed to participate in the study.

For this study, approximately 60 patients diagnosed with ASPD were interviewed; 5 people were excluded from the study because they did not agree to participate in the study. Of the remaining 55 patients; 1 patient was excluded from the study for obesity, 6 patients for alcohol/substance use disorder, 1 patient for Type 1 Diabetes Mellitus disease and 2 patients for not filling in the scales given completely. Sociodemographic data form, Beck Depression Inventory (BDI), Beck Anxiety Inventory (BAI), Barratt Impulsivity Scale (BIS-11), Buss-Durke Hostility Inventory (BDHI) were applied to all participants.

\section{Data collection tools}

Sociodemographic data form was prepared by the researchers in accordance with the aims of the study, and the literature review. Demographic data such as age, marital status, educational status, place of residence, employment status and economic level, as well as alcohol/substance use, smoking, marks of cuts and tattoos on the body, status of serving in prison before and the type of crime were investigated. Height and weight measurements of all participants were made with the same weighing model in the hospital.

\section{Beck Depression Inventory (BDI)}

It is used to measure the level and severity of depressive symptoms in adults. It is a 21-point, Likert-type self-report inventory and the items are scored between $0-3$. A score between $0-63$ can be obtained from the inventory and the cutoff score has been calculated as $17 \cdot{ }^{14,15}$

\section{Beck Anxiety Inventory (BAI)}

It is used to determine the frequency and severity of anxiety symptoms experienced by the person. It is a 21-point Likert-type self-report scale with items scored between $0-3$. It has been reported that the anxiety experienced by the person increases as the obtained score increases. ${ }^{16,17}$

\section{Barratt Impulsivity Scale (BIS-11)}

It is a 30-item self-report scale used to evaluate impulsivity. It consists of three subscales: 1) attentional (cognitive instability, attention), 2) nonplanning (cognitive complexity, selfcontrol), 3) motor (motor, perseverance) and the total score is calculated. It was stated that as the total score obtained from the scale increases, the level of impulsivity increases. It was developed by Patton et al., ${ }^{18}$ and was translated into Turkish by Güleç et al. ${ }^{19}$

\section{Buss-Durke Hostility Inventory (BDHI)}

It was developed to measure the aggression potential of individuals. It is a 34-point Likert-type self-report inventory with each item scored between 1 and 5. Its sub-dimensions are physical aggression, verbal aggression, anger, hostility, and indirect aggression. In addition, the total aggression level is calculated with the total score and high scores indicate that the aggression tendency is high..$^{20,21}$

\section{Analysis of samples}

Peripheral venous blood samples were collected from all participants when they were hungry and at the same time of the day before the patients started treatment. The blood samples were taken into tube containing aproprotein (BD Vacutainer SST II, Plymouth, UK). The blood samples collected 
were centrifuged for 10 minutes (4000 rpm) in two hours and the separated serums were stored at $-70^{\circ} \mathrm{C}$ until the day of analysis. After the collection of blood was completed, nesfatin-1 hormone levels were measured with a Human Nesfatin-1 ELISA kit (Sunred Biological Technology, catalog number: SRBT-88603, Shanghai, China) by the ELISA method. Absorbance measurements were made on Chromate 4300 Microplate Reader device.

\section{Statistical analysis}

SPSS for Windows software (Statistical Package for Social Sciences for Windows, ver. 20) was used for statistical evaluation of the data from the participants. Descriptive analysis to give information about the general characteristics of the participants were given in the form of frequencies, percentage distribution and mean \pm standard deviation. The data on continuous variables were presented in the form of mean \pm standard deviation; the data on categorical variables were presented in numbers ( $\mathrm{n} ; \%)$.

The qualitative variables of the study were; demographic data such as gender, age, educational background, economic status and smoking status and/or alcohol use and presence of additional diseases. Cross-tabulation and chi-square tests were used to evaluate whether there was a relationship between qualitative variables. The quantitative variables were the scores obtained from the scales applied to the participants and nesfatin-1 hormone values. When evaluating whether there was a relationship between quantitative variables. Significance of the Difference between Two Means test and Mann Whitney $U$ test was used. $\mathrm{p}$ values below 0.05 were considered statistically significant.

\section{RESULTS}

A total of 90 participants were included in the study; 45 people were diagnosed with ASPD according to DSM-5 criteria, and 45 people were included as the healthy control group. All participants were male. The sociodemographic data of the participants are presented in Table 1.

When the relationship between quantitative variables was examined, it was found that anxiety and depression scores of patients with personality disorders were higher than those of the healthy controls ( $\mathrm{p}<0.001$ for both scales). In the personality disorder group, 30 people (67\%) passed the cut-off score for BDI, while 25 people (56\%) scored 20 points or more for BAI. In the healthy control group; while $4(8.8 \%)$ people passed the cut-off score for BDI, only 2 (4.4\%) achieved a score of 20 or more for BAI. For BIS-11; the score of motor impulsivity and non-planning impulsivity subscales were higher than those of the healthy controls ( $\mathrm{p}$ values; $<0.001,0.036$, respec- tively). For BDHI; the scores of the personality disorder group were much higher in all sub-dimensions and in the overall total of the inventory $(\mathrm{p}<0.05)$ (Table 2$)$.

Table 1. Sociodemographic characteristics of the participants

\begin{tabular}{|c|c|c|c|}
\hline & $\begin{array}{l}\text { Healthy } \\
\text { control } \\
\text { group } \\
(\mathrm{N}=45) \\
\mathrm{N}(\%)\end{array}$ & $\begin{array}{c}\text { Patients } \\
\text { diagnosed } \\
\text { with antisocial } \\
\text { personality } \\
\text { disorder } \\
(\mathrm{N}=45) \\
\mathrm{N}(\%)\end{array}$ & $\mathrm{p}$ \\
\hline Sex (male/female) & $45 / 0$ & $45 / 0$ & \\
\hline $\begin{array}{l}\text { Marital status } \\
\text { (single/married) }\end{array}$ & $\begin{array}{c}17 / 28 \\
(37.8 / 62.2)\end{array}$ & $\begin{array}{c}33 / 12 \\
(73.3 / 26.7)\end{array}$ & 0.001 \\
\hline \multicolumn{4}{|l|}{ Educational status } \\
\hline Literate & $0(0)$ & $7(15.6)$ & \\
\hline Primary school graduate & $2(4.4)$ & $8(17.8)$ & \\
\hline Middle school graduate & $6(13.3)$ & $20(44.4)$ & $<0.001$ \\
\hline High school graduate & $13(28.9)$ & $4(8.9)$ & \\
\hline University student & $24(53.3)$ & $6(13.33)$ & \\
\hline \multicolumn{4}{|l|}{ Employment status } \\
\hline Unemployment & $0(0)$ & $17(37.8)$ & \\
\hline Construction worker & $8(17.8)$ & $23(51.1)$ & \\
\hline Tradesman & $0(0)$ & $5(11.11)$ & $<0.001$ \\
\hline Medical officer & $29(69.4)$ & $0(0)$ & \\
\hline Military personnel & $8(17.8)$ & $0(0)$ & \\
\hline $\begin{array}{l}\text { Alcohol use } \\
\text { (yes/no/withdrawn) }\end{array}$ & $\begin{array}{c}3 / 40 / 2 \\
(6.7 / 88.9 / 4.4)\end{array}$ & $\begin{array}{c}15 / 16 / 14 \\
(33.3 / 35.6 / 31.1)\end{array}$ & $<0.001$ \\
\hline $\begin{array}{l}\text { Substance use } \\
\text { (yes/no/withdrawn) }\end{array}$ & $\begin{array}{c}0 / 45 / 0 \\
(0 / 100 / 0)\end{array}$ & $\begin{array}{c}10 / 17 / 18 \\
(22.2 / 37.8 / 40)\end{array}$ & $<0.001$ \\
\hline Smoking use (yes/no) & $\begin{array}{c}12 / 33 \\
(26.7 / 73.33)\end{array}$ & $\begin{array}{c}3 / 42 \\
(6.6 / 93.3)\end{array}$ & 0.010 \\
\hline Tattoos on body (yes/no) & $\begin{array}{c}0 / 45 \\
(0 / 100)\end{array}$ & $\begin{array}{c}39 / 6 \\
(86.7 / 13.3)\end{array}$ & $<0.001$ \\
\hline Being prison (yes/no) & $\begin{array}{c}0 / 45 \\
(0 / 100)\end{array}$ & $\begin{array}{c}28 / 17 \\
(62.2 / 37.8)\end{array}$ & $<0.001$ \\
\hline
\end{tabular}

Type of crime

Bodily harm

Selling drugs

Willful murder

Thieft/plunderage

Membership of armed terrorist organization

Height

$175.78 \pm 6.15 \quad 174.11 \pm 6.11 \quad 0.055$

Weight

$75.58 \pm 10.88 \quad 72.84 \pm 11.18 \quad 0.243$

$10(34.5)$

$4(13.8)$

$3(10.3)$

8 (27.6)

$3(10.3)$

None of the participants required medical treatment. Chi-square test was used in calculations. $\mathrm{p}<0.05$ was considered statistically significant 
When the laboratory parameters were examined, no difference was observed in the sodium and potassium electrolytes of the participants ( $\mathrm{p}$ values; $0.729,0.207$ respectively).

Table 2. Quantitative variable distribution of the participants

\begin{tabular}{lccc}
\hline & $\begin{array}{c}\text { Healthy control } \\
\text { group }(\mathrm{N}=45) \\
(\text { Mean } \pm \text { SD })\end{array}$ & $\begin{array}{c}\text { Antisocial } \\
\text { personality } \\
\text { disorder } \\
\text { patient }(\mathrm{N}=45) \\
(\text { Mean } \pm \text { SD })\end{array}$ & p \\
\hline BAI & $4.52 \pm 5.85$ & $23.29 \pm 16.49$ & $<0.001$ \\
BDI & $4.20 \pm 6.54$ & $26.11 \pm 17.17$ & $<0.001$ \\
BIS-11 & $29.16 \pm 6.12$ & $30.47 \pm 5.09$ & 0.276 \\
Attentional & $11.11 \pm 1.96$ & $15.16 \pm 4.60$ & $<0.001$ \\
Motor & $17.93 \pm 4.01$ & $19.51 \pm 2.91$ & 0.036 \\
Nonplanning & & & \\
BDHI & $2.66 \pm 1.58$ & $4.62 \pm 2.04$ & $<0.001$ \\
Physical aggression & $3.09 \pm 1.24$ & $3.71 \pm 1.58$ & 0.042 \\
Indirect aggression & $3.11 \pm 2.09$ & $5.07 \pm 1.96$ & $<0.001$ \\
Feeling anger & $2.25 \pm 1.53$ & $3.64 \pm 1.34$ & $<0.001$ \\
Hostility & $6.98 \pm 2.87$ & $10.11 \pm 2.47$ & $<0.001$ \\
Verbal aggression & $17.95 \pm 7.02$ & $27.04 \pm 7.05$ & $<0.001$ \\
\hline General aggression & & & \\
\hline
\end{tabular}

The significance test of the difference between two means was used. $\mathrm{p}<0.05$ was considered statistically significant. BAI: Beck Anxiety Inventory, BDI: Beck Depression Inventory, BIS-11: Barratt Impulsivity Scale, BDHI: Buss-Durkee Hostility Inventory

Table 3. The results of the laboratory parameters of the participants

\begin{tabular}{lccc}
\hline & $\begin{array}{c}\text { Healthy control } \\
\text { group (N=45) } \\
(\text { Mean } \pm \text { SD) }\end{array}$ & $\begin{array}{c}\text { Antisocial } \\
\text { personality } \\
\text { disorder }(\mathrm{N}=45) \\
(\text { Mean } \pm \text { SD) }\end{array}$ & $\mathrm{p}$ \\
\hline fT3 & $3.12 \pm 0.86$ & $3.56 \pm 0.75$ & 0.005 \\
fT4 & $2.21 \pm 5.01$ & $0.81 \pm 0.10$ & 0.002 \\
TSH & $2.32 \pm 3.35$ & $1.59 \pm 0.80$ & 0.729 \\
Vitamin B12 & $156 \pm 82.20$ & $155.69 \pm 40.77$ & 0.991 \\
Glucose & $88.70 \pm 16.56$ & $89.89 \pm 18.43$ & 0.779 \\
Urea & $30.20 \pm 7.61$ & $26.26 \pm 9.49$ & 0.061 \\
Creatinine & $0.98 \pm 0.77$ & $0.84 \pm 0.28$ & 0.247 \\
AST & $23.14 \pm 13.41$ & $26.67 \pm 13.54$ & 0.059 \\
ALT & $26.64 \pm 22.16$ & $31.51 \pm 40.02$ & 0.996 \\
Cholesterol & $164.83 \pm 52.99$ & $181.56 \pm 48.70$ & 0.172 \\
HDL & $42.72 \pm 10.33$ & $41.16 \pm 7.89$ & 0.463 \\
LDL & $103.24 \pm 36.53$ & $107.26 \pm 35.70$ & 0.651 \\
Triglycerides & $123.54 \pm 69.01$ & $193.76 \pm 21.79$ & 0.106 \\
Nesfatin-1-hormone & $7.06 \pm 4.14$ & $5.34 \pm 3.76$ & 0.044 \\
\hline
\end{tabular}

Mann Whitney $\mathrm{U}$ test was used in the calculations. The values given in the table are presented as mean \pm standard deviation. fT3: free thyroid hormone-3, fT4: free thyroid hormone-4, TSH: thyroid stimulating hormone
There was no significant difference between fasting blood sugar, urea, creatinine, liver enzymes (AST and ALT), total cholesterol, HDL and LDL cholesterol values ( $p>0.05$ ). For the Nesfatin-1 hormone level, the values of the personality disorder group were $5.34 \pm 3.76$, while those of the healthy control group were $7.06 \pm 4.14$ ( $\mathrm{p}=0.044)$ (Table 3). According to the results of the correlation analysis, a positive strong correlation was found between BAI and BDI and motor impulsivity, physical aggression, indirect aggression, anger, and general aggression subscales $(p<0.05)$. No relationship was found between the nesfatin- 1 hormone and any other laboratory parameters and applied scales ( $\mathrm{p}>0.05)$.

\section{DISCUSSION}

In our study, the impulsivity, aggression, and the nesfatin-1 hormone levels of the group diagnosed with ASPD were compared with those of the healthy controls. Our results revealed that both anxiety and depression scores of the personality disorder group were higher than those of the healthy controls. It was also found that they had higher impulsivity levels in certain areas and aggression levels in all areas. They were found to have lower levels of the nesfatin-1 hormone than the healthy controls. A relationship between the nesfatin-1 hormone and impulsivity and aggression scores could not be found.

In the literature, there is no study investigating nesfatin-1 hormone levels in relation to personality disorder. Our results showed that nesfatin-1 hormone levels were low in people with antisocial personality disorder compared to healthy controls. The most frequently studied disease group in psychiatry in terms of nesfatin- 1 hormone is patients with MDD. ${ }^{8,22,23}$ The nesfatin-1 hormone was found to be higher in patients with MDD than in healthy controls. Furthermore, it was found that hormone levels increased with an increase in depression severity. ${ }^{8,22}$ It was also suggested that nesfatin-1 hormone can be used as a non-invasive biomarker for depression disorder. ${ }^{23}$ It was determined in the literature that the nesfatin- 1 hormone may have a potential role in anxiety disorders. ${ }^{24}$ In fact, it was reported that there is a positive correlation between the severity of anxiety experienced by patients and the nesfatin-1 hormone. ${ }^{25}$ It was found in our results that nesfatin-1 hormone levels of the antisocial personality disorder group were significantly lower than those of the healthy controls. Although depression and anxiety scores were higher in the personality disorder group than in the healthy controls, no significant increase was detected in nesfatin-1 hormone levels. There was no correlation between BDI, BAI, BIS-11, BDHI which were applied to the participants and hormone levels. In a study conducted on patients with alcohol abuse disorder, nesfatin-1 hormone levels were compared with those of the healthy con- 
trols at different stages of alcohol withdrawal. As a result of the comparison with the healthy controls at the beginning of treatment, significantly lower hormone values, similar to our results, were obtained. ${ }^{12}$ Similar to our results, in a study conducted on patients with a bipolar disorder-manic period, nesfatin-1 hormone levels were found to be lower than those of the healthy controls. ${ }^{11}$ It was reported that bipolar disorder had an interaction with cluster B personality disorders, including borderline personality disorder and antisocial personality disorder. Bipolar disorder and cluster B personality disorders were associated with features such as self-destruction behavior, impulsivity, being involved in crime. ${ }^{26}$ Our results, similar to those in a study investigating nesfatin-1 hormone levels in bipolar disorder, showed that nesfatin-1 hormone levels were low.

Some studies in the literature reported differences between genders in terms of nesfatin-1 hormone levels. While it was found that hormone levels also increased with an increase in anxiety levels in women, there was a reverse situation for men. In other words, anxiety scores increased in men while nesfatin-1 hormone levels decreased. ${ }^{27}$ In studies conducted on patients with MDD, no gender differences were detected. Nesfatin-1 hormone levels in both sexes were found to be high in patients with MDD. ${ }^{8,22}$ In our study, the personality disorder group and the control group consisted of males. Since all our participants were male, no gender differences were detected.

The nesfatin-1 hormone is secreted from the hypothalamus and brain stem and controls food intake and energy metabolism. It was found that its secretion decreased during fasting and hunger. ${ }^{28}$ There is a significant negative correlation between the nesfatin-1 hormone and weight and Body Mass Index. ${ }^{29}$ Since there was no significant difference between the height and weight of our participants, no relation was found between hormone levels and height/weight. It was found that nesfatin-1 hormone levels in patients with a bipolar disorder-manic period were low in comparison with those of the healthy controls. Additionally, after patients reached the remission period, an insignificant increase occurred in hormone levels. It has been reported that this may contribute to the mania and high energy levels of the patients. ${ }^{11}$ Similarly, it was thought that the low levels of the nesfatin-1 hormone in the ASPD group may contribute to their aggression and impulsivity in a similar way to manic attack.

Considering the effect of high blood sugar on the nesfatin-1 hormone, patients diagnosed with diabetes mellitus were not included in the study. In terms of thyroid functions, while TSH values did not differ between the personality disorder group and the healthy controls; the values of sT3 were found to be high, and sT4 were found to be low in the ASPD group. It was reported in a study in the literature that sT3 values were low and sT4 values were high in patients with ASPD. In the same study, when the ASPD group was divided into two as involved and not involved in crime; the sT3 values of the group involved in the crime were found to be higher than those of the other group, which were similar to our findings. The aggression levels of the ASPD group showed a correlation with sT3 values. ${ }^{30}$ In a study of borderline personality disorder, which is among the DSM-5 "cluster B personality disorders", like ASPD, sT3 values were found to be high; and aggression, impulsivity correlated with sT3 values. ${ }^{31}$ In a study examining nesfatin-1 hormone levels in MDD patients; It was determined that there was a positive relationship between TSH values and hormone values. ${ }^{8}$ In our results, however, the nesfatin-1 hormone did not correlate with any laboratory parameters.

As a result of the characteristics of the socio-demographic data, since all the participants in the personality disorder group consisted of males, the healthy control group also consisted of males. It was reported that antisocial personality disorder is more common in the male gender, which is similar to our results. ${ }^{32}$ The majority of the personality disorder group consisted of individuals with a low level of education, compared to the control group most of whom were single and healthy. This result is compatible with the findings of many studies in the literature. The people in the antisocial personality disorder group were reported to be unable to complete their education before the age of 15 due to factors such as behavioral disorders, impulsivity, violations of rights, which are included in the DSM5 diagnostic criteria. ${ }^{33}$ The rates of smoking, alcohol and substance use were much higher in the personality disorder group than in the control group. This result is compatible with the literature and the diagnostic criteria of antisocial personality disorder. ${ }^{32-34}$ In accordance with DSM-5 diagnostic criteria, most of the people in the ASPD group had been in prison for at least one crime. In addition, most of them had a tattoo on their body and an incision scar they made themselves.

Depression and anxiety scores of the scales we applied were higher in the personality disorder group compared to the control group. It has been reported in many studies in the literature that the frequency of alcohol and substance use along with MDD, and common anxiety disorder diagnosed with Axis 1 are higher in people with antisocial personality disorder. ${ }^{35,36}$ Additionally, it was determined from our results that aggression levels of the personality disorder group increased in all areas including physical aggression, verbal aggression, anger, hostility, indirect aggression, and general aggression. It was determined that they also had higher levels of motor impulsivity and designed impulsivity.

Our results should be evaluated considering some limitations. The first of these limitations is the relatively insufficient number of participants. It is among the limitations that all par- 
ticipants were male and we worked on a single type of personality disorder. These limitations prevent the generalization and interpretation of the results we obtained. In order for our results to gain importance, further research is required in larger sample groups, different genders, and different personality disorder groups.

\section{Conclusion}

Our study is the first study in the literature that examines nesfatin-1 hormone levels in personality disorder patients. Nesfatin-1 hormone levels in antisocial personality disorder patients involved in at least one crime were found to be lower compared to those of the healthy controls. As expected, the impulsivity and aggression levels of the personality disorder group were found to be higher. Further research should be done to detect the relationship of the nesfatin- 1 hormone as a neuropeptide in personality disorder.

\section{Acknowledgments}

None.

\section{Conflicts of Interest}

The authors have no potential conflicts of interest to disclose.

\section{Author Contributions}

Conceptualization: Filiz Özsoy. Data curation: Şüheda Kaya, Gülay Taşcı. Formal analysis: Filiz Özsoy. Funding acquisition: all authors. Investigation: all authors. Methodology: Şuheda Kaya, Filiz Özsoy, Gülay Taşcı. Project administration: Şüheda Kaya, Gülay Taşc1. Resources: Filiz Özsoy. Software: all authors. Supervision: all authors. Validation: all authors. Writing-original draft: Filiz Özsoy. Writing—review \& editing: all authors.

\section{ORCID iDs}

$\begin{array}{ll}\text { Şuheda Kaya } & \text { https://orcid.org/0000-0002-0853-5777 } \\ \text { Filiz Özsoy } & \text { https://orcid.org/0000-0002-5198-8827 } \\ \text { Gülay Taşci } & \text { https://orcid.org/0000-0003-2078-0182 } \\ \text { Mehmet Kalaycl } & \text { https://orcid.org/0000-0001-9122-9289 }\end{array}$

\section{REFERENCES}

1. Jiang W, Shi F, Liao J, Liu H, Wang T, Shen C, et al. Disrupted functional connectome in antisocial personality disorder. Brain Imaging Behav 2017;11:1071-1084.

2. Yang Y, Raine A. Prefrontal structural and functional brain imaging findings in antisocial, violent, and psychopathic individuals: a metaanalysis. Psychiatry Res 2009;174:81-88.

3. Kumari V, Uddin S, Premkumar P, Young S, Gudjonsson GH, Raghuvanshi $\mathrm{S}$, et al. Lower anterior cingulate volume in seriously violent men with antisocial personality disorder or schizophrenia and a history of childhood abuse. Aust N Z J Psychiatry 2014; 48:153-161.

4. Sundram F, Deeley Q, Sarkar S, Daly E, Latham R, Craig M, et al. White matter microstructural abnormalities in the frontal lobe of adults with antisocial personality disorder. Cortex 2012;48:216-229.

5. Fairchild G, Baker E, Eaton S. Hypothalamic-pituitary-adrenal Axis function in children and adults with severe antisocial behavior and the impact of early adversity. Curr Psychiatry Rep 2018;20:84.

6. Poustka L, Maras A, Hohm E, Fellinger J, Holtmann M, Banaschewski $\mathrm{T}$, et al. Negative association between plasma cortisol levels and aggression in a high-risk community sample of adolescents. J Neural Transm
2010;117:621-627.

7. Böhnke R, Bertsch K, Kruk MR, Naumann E. The relationship between basal and acute HPA axis activity and aggressive behavior in adults. J Neural Trans 2010;117:629-637.

8. Xiao MM, Li JB, Jiang LL, Shao H, Wang BL. Plasma nesfatin-1 level is associated with severity of depression in Chinese depressive patients. BMC Psychiatry 2018;18:88.

9. Pałasz A, Krzystanek M, Worthington J, Czajkowska B, Kostro K, Wiaderkiewicz R, et al. Nesfatin-1, a unique regulatory neuropeptide of the brain. Neuropeptides 2012;46:105-112.

10. Hofmann T, Ahnis A, Elbelt U, Rose M, Klapp BF, Stengel A. NUCB2/ nesfatin-1 is associated with elevated levels of anxiety in anorexia nervosa. PLoS One 2015;10:e0132058.

11. Emul M, Karamustafalıŏlu N, Kalelioğlu T, Genç A, Taşdemir A, Güngör FC, et al. The nesfatin 1 level in male patients with manic episode and alterations of nesfatin 1 level after antipsychotic and electroconvulsive treatment. J Affect Disord 2013;151:849-853.

12. Umut G, Evren C, Cansız A, Akkuş M, Karamustafalığlu N. Serum NUCB2/nesfatin-1 levels in different stages of alcohol dependence: Is there a relationship with craving?. Indian J Psychiatry 2017;59:94-99.

13. Riis P. Thirty years of bioethics: the Helsinki Declaration 1964-2003. New Rev Bioeth 2003;1:15-25.

14. Beck AT, Ward CH, Mendelson M, Mock J, Erbaugh J. An inventory form easuring depression. Arch Gen Psychiatry 1961;4:561-571.

15. Hisli N. A Study on the Validity of Beck Depression Inventory. Turk Psychol J 1989;22:118-126.

16. Beck AT, Epstein N, Brown G, Steer RA. An inventory form measuring clinical anxiety: Psychometric properties. J Consult Clin Psychol 1988; 56:893-897.

17. Ulusoy M, Şahin N, Erkman H. Turkish version of the beck anxiety inventory: psychometric properties. J Cogn Psychother 1998;12:28-35.

18. Patton JH, Stanford MS, Barratt ES. Factor structure of the Barratt Impulsivity Scale. J Clin Psychol 1995;51:768-774.

19. Güleç H, Tamam L, Güleç MY, Turhan M, Karakuş G, Zengin M, et al. Psychometric properties of the Turkish version of the Barratt Impulsivity Scale-11. Klinik Psikofarmakol Bulteni 2008;18:251-258.

20. Buss AH, Durkee A. An inventory for assessing different kinds of hostility. J Consult Psychol 1957;21:343-349.

21. Can S. "Aggression questionnaire" adlı ölçeğin Türk popülasyonunda geçerlilik ve güvenilirlik Çalışması. Genel Kurmay Başkanlığı, Gülhane Askeri Tıp Akademisi Haydarpaşa Eğitim Hastanesi Ruh Sağlı̆̆ı ve Hastalıkları Servis Şefliği. (Turkish). Istanbul: Unpublished Specialty Thesis; 2002.

22. Algul S, Özçelik O. Evaluating the levels of nesfatin-1 and ghrelin hormones in patients with moderate and severe major depressive disorders. Psychiatry Investig 2018;15:214-218.

23. Xu YY, Ge JF, Liang J, Cao Y, Shan F, Liu Y, et al. Nesfatin-1 and cortisol: potential novel diagnostic biomarkers in moderate and severe depressive disorder. Psychol Res Behav Manag 2018;11:495-502.

24. Weibert E, Hofmann T, Stengel A. Role of nesfatin-1 in anxiety, depression and the response to stress. Psychoneuroendocrinology 2019;100: 58-66.

25. Hofmann T, Stengel A, Ahnis A, Busse P, Elbelt U, Klapp BF. NUCB2/ nesfatin-1 is associated with elevated scores of anxiety in female obese patients. Psychoneuroendocrinology 2013;38:2502-2510.

26. Swann AC, Lijffijt M, Lane SD, Steinberg JL, Moeller FG. Antisocial personality disorder and borderline symptoms are differentially related to impulsivity and course of illness in bipolar disorder. J Affect Disord 2013;148:384-390.

27. Hofmann T, Elbelt U, Ahnis A, Rose M, Klapp BF, Stengel A. Sex-specific regulation of NUCB2/nesfatin-1: differential implication in anxiety in obese men and women. Psychoneuroendocrinology 2015;60:130-137.

28. Ayada C, Toru Ü, Korkut Y. Nesfatin-1 and its effects on different systems. Hippokratia 2015;19:4-10.

29. Alotibi MN, Alnoury AM, Alhozali AM. Serum nesfatin-1 and galanin 
concentrations in the adult with metabolic syndrome: relationships to insulin resistance and obesity. Saudi Med J 2019;40:19-25.

30. Evrensel A, Ünsalver BÖ, Özşahin A. The relationship between aggression and serum thyroid hormone level in individuals diagnosed with antisocial personality disorder. Noro Psikiyatr Ars 2016;53:120-125.

31. Sinai C, Hirvikoski T, Nordström AL, Nordström P, Nilsonne A, Wilczek A, et al. Thyroid hormones and adult interpersonal violence among women with borderline personality disorder. Psychiatry Res 2015;227 (2-3):253-257.

32. Black DW. The natural history of antisocial personality disorder. Can J Psychiatry 2015;60:309-314.

33. Werner KB, Few LR, Bucholz KK. Epidemiology, comorbidity, and be- havioral genetics of antisocial personality disorder and psychopathy. Psychiatr Ann 2015;45:195-199.

34. Regier DA, Kuhl EA, Kupfer DJ. The DSM-5: classification and criteria changes. World Psychiatry 2013;12:92-98.

35. Trull TJ, Jahng S, Tomko RL, Wood PK, Sher KJ. Revised NESARC personality disorder diagnoses: gender, prevalence, and comorbidity with substance dependence disorders. J Pers Disord 2010;24:412-426.

36. Brook JS, Zhang C, Rubenstone E, Primack BA, Brook DW. Comorbid trajectories of substance use as predictors of antisocial personality disorder, major depressive episode, and generalized anxiety disorder. Addict Behav 2016;62:114-121. 